\title{
BISPHOSPHONATE-INDUCED MAXILLOFACIAL OSTEONECROSIS IN OSTEOPOROTIC INDIVIDUALS
}

\section{ABSTRACT}

Bisphosphonate-related osteonecrosis of the maxillae may be an important complication of long-term osteoporosis treatment. The possibility of osteonecrosis of the maxillae in patients exposed to nitrogenated bisphosphonates was first described in 2003. Since then, case reports and retrospective studies have demonstrated higher percentages of occurrence of osteonecrosis in patients who have used or are using bisphosphonates. Although this complication may be spontaneous, invasive oral procedures have a role as risk factors associated with dental procedures such as tooth extractions and other bone operations. In addition, tooth infections and periodontal disease have been reported to be the main risk factors for development of bisphosphonate-induced osteonecrosis of the maxillae. For this reason, dentists, general clinicians, orthopedists, geriatricians and oralmaxillofacial surgeons need to be aware of this problem and work in a multidisciplinary environment, thereby stimulating early diagnosis and prevention of further potential cases.

Keywords - Osteoporosis; Bisphosphonates; Facial Bones

\section{INTRODUCTION}

Osteoporosis is a common disease characterized by low bone mass and structural deterioration of the bone tissue, thus giving rise to diminished bone strength and increased susceptibility to fractures $^{(1)}$. At the menopause, the decrease in estrogen production leads to an imbalance in bone remodeling. Bone reabsorption occurs at a higher rate than bone formation does, which results in progressive bone loss and leads to postmenopausal osteoporosis and increased risk of fractures due to frailness ${ }^{(2)}$. In postmenopausal women and in men aged 50 years or over, vertebral fractures may occur and may trigger chronic diseases and deformities, both in the hips and femoral head and in the spine, where such fractures are associated with increased morbidity and mortality, and a substantial economic impact $^{(3)}$. Therefore, clinical examinations for diagnosing and assessing the risk of fractures and for measuring bone mineral density are fundamental for following up this group of patients ${ }^{(4)}$.

1 - MSc and PhD on Oral Pathology; Professor in the Department of Stomatology, Bauru School of Dentistry, University of São Paulo, Bauru, SP, Brazil.

2 - MSc and PhD in Oral Pathology; Preceptor of the Special Patients' Care Center, School of Dentistry, University of São Paulo, São Paulo, SP, Brazil.

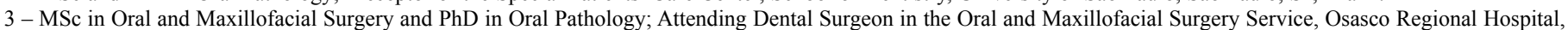
São Paulo, SP, Brazil.

Work performed in the School of Dentistry, University of São Paulo, São Paulo, SP, Brazil.

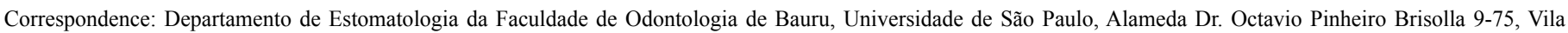
Universitária, 17012-901 Bauru, SP. E-mail: paulosss@fob.usp.br

Work received for publication: January 11, 2011; accepted for publication: March 25, 2011. 
Bone metabolism is characterized by two simultaneous and opposite activities: bone deposition and reabsorption. During bone deposition, osteoblasts synthesize a matrix that undergoes primary mineralization followed by a long process of secondary mineralization. It is now known that osteoblastic differentiation is controlled by genes of the Hedgehog family (Indian Hedgehog and Sonic Hedgehog), transcription factor Cbfa-1 and bone morphogenetic proteins (BMPs), which are the most potent regulators of osteoblastic differentiation originating from undifferentiated mesenchymal cells ${ }^{(5)}$.

Bone reabsorption is performed by osteoclasts and consists of bone mineral dissolution and catabolism of the bone matrix components. Osteoclasts are large $(100 \mu \mathrm{m})$ multinucleated cells that are rich in mitochondria and vacuoles containing tartrateresistant acid phosphatase, and which enable dephosphorylation of bone proteins. It is now known that the metabolism of osteoclastogenesis is dependent on osteoblasts and is regulated by three key molecules: osteoprotegerin (OPG), receptor activator of NF-kB ligand (RANKL) and receptor activator of NF-kB (RANK). RANKL is a member of the superfamily of tumor necrosis factors (TNF), and it is synthesized by osteoblasts, bone marrow stromal cells, T lymphocytes and endothelial cells. In binding to RANK (which is expressed in the precursors of osteoclasts, T lymphocytes and endothelial cells), the function of RANKL is to activate the osteoclasts, which leads to formation of multinucleated cells ${ }^{(6)}$. In bone tissue, RANKL activity is increased and OPG activity is decreased through action by PTH, glucocorticoids and prostaglandin E2. On the other hand, the effects of RANKL are blocked by OPG, which acts as an antagonist receptor for RANKL, thereby preventing bone reabsorption ${ }^{(6)}$.

Therapeutic interventions that attenuate the risk of fractures are essential for reducing the consequences of this condition. Currently, the first-line treatment for osteoporosis is nitrogen-bearing bisphosphonates (BFs) such as alendronate, risedronate and ibandronate, which are agents for inhibiting bone reabsorption ${ }^{(7,8)}$. BF medications are synthetic analogues of inorganic pyrophosphate: they are endogenous regulators of bone mineralization and have chelating action on calcium ions, thereby binding the ions to the hydroxyapatite of the bone surfaces that are undergoing remodeling. They potentially reduce the bone reabsorption rate because they inhibit mature osteoclasts and recruitment of their precursors. BFs are a class of medications that impede bone mass loss through inhibition of RANKL, which thus blocks the differentiation and activation of osteoclasts and consequently reduces pain and the risk of pathological fractures ${ }^{(6,9,10)}$.

In the literature, osteonecrosis induced by bisphosphonates (ONB) was initially addressed in 2003, by Migliorati(11), Marx ${ }^{(12)}$, Wang et al ${ }^{(13)}$ and Carter and Goss ${ }^{(14)}$, who reported cases of patients with extensive osteolytic lesions similar to osteomyelitis in the maxillary bones. The origin of these lesions was attributed to therapy using high doses of BFs ${ }^{(15,16)}$ (Figures 1, 2 and 3). Since then, case reports and retrospective studies have demonstrated occurrences of osteonecrosis of the maxillary bones, either with or without accompanying dentoalveolar surgical manipulation $^{(17,18)}$. Mechanisms involving microcirculation disorders, with the appearance of microthrombi that impede vascularization at the site, and involving inhibition of angiogenic factors such as the vascular angiogenic growth factor, have also been described ${ }^{(19)}$. The modifications to vascularization that are inherent to ONB partly explain why the mandible is affected more than the maxilla is, given that the former has anatomically less vascularization than the latter does. The gnathic bones, and especially the mandible, would be the locations of choice for ONB because they are the only bones susceptible to constant microtraumas, because of the presence of the teeth, which stimulates constant bone turnover. In turn, the teeth are an entry point for pathogenic microorganisms along endodontic or periodontics routes, which facilitates establishment of infectious and inflammatory foci, for which repair is compromised by $\mathrm{BFs}^{(20-23)}$.

Studies have indicated that bacterial infections have a role in $\mathrm{ONB}^{(23,24)}$. Colonization by Actinomyces, Staphylococcus aureus and Streptococcus $s p^{(25)}$ and by bacteria of the normal flora of the oral cavity ${ }^{(21)}$ has been detected. In this respect, therapy with antibiotics is fundamental for disease control. Cofactors such as smoking, diabetes, use of steroids and other medications, anemia, hypoxia and kidney disorders ${ }^{(19)}$ cannot be dismissed in the pathogenesis of ONB. 
In 2009, the American Association of Oral and Maxillofacial Surgeons (AAOMS) established recommendations regarding the risk of developing ONB and its treatment. An expert committee defined ONB as persistent exposure of necrotic bone in the maxillofacial region, for more than eight

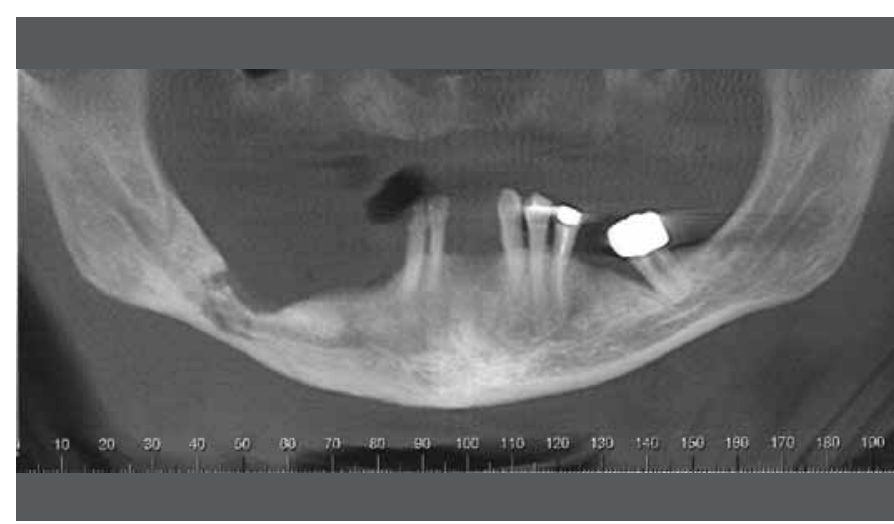

Figure 1 - Panoramic radiograph showing extensive involvement of the mandible, with bone lesion in the right posterior portion.

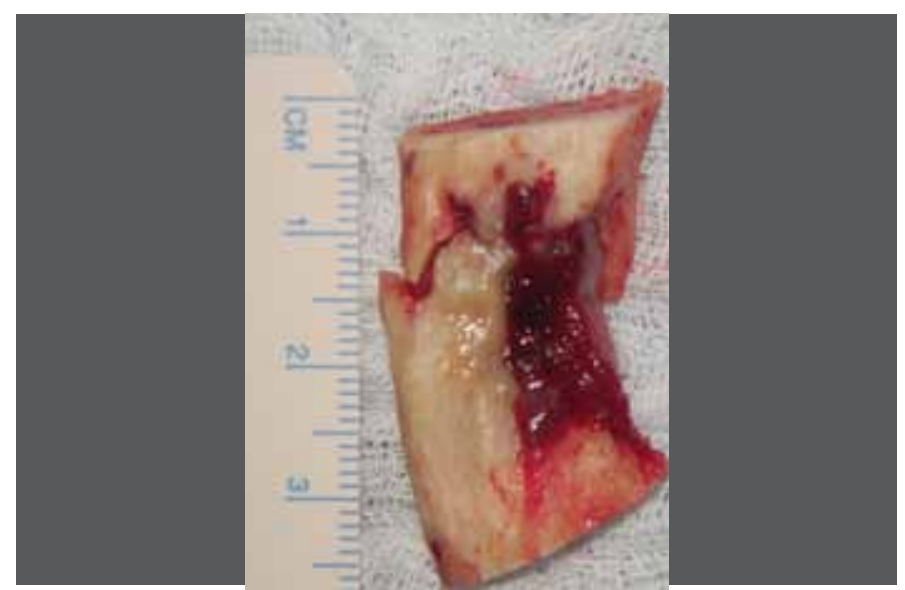

Figure 2 - Surgical specimen from mandible showing extensive ONB with pathological fracture.

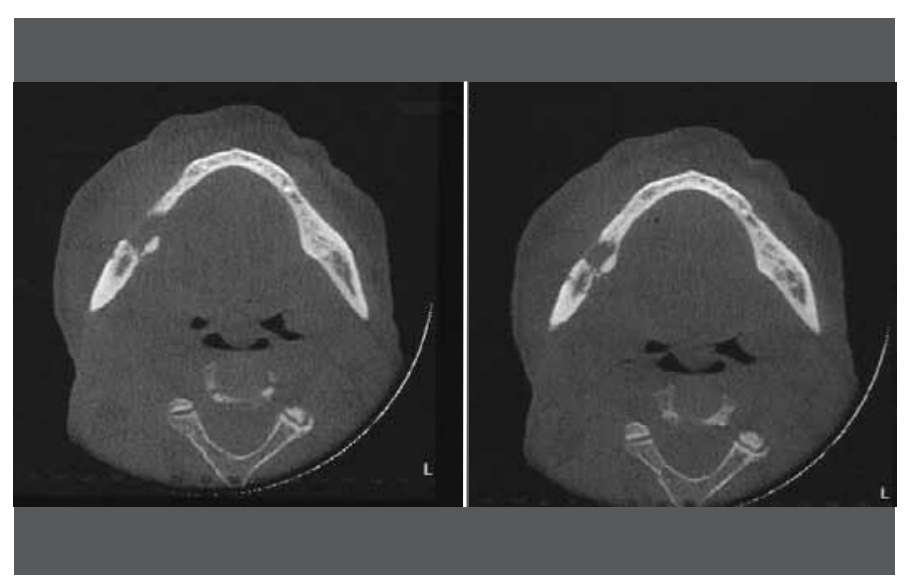

Figure 3 - Computed tomography image showing extensive mandibular bone destruction. weeks, in individuals without any history of previous radiotherapy in the neck region, who had used or were using bisphosphonates ${ }^{(19)}$. From the scientific literature scrutinized up to that date, the AAOMS emphasized that the knowledge available on the relationship between bisphosphonates and necrosis of maxillary bones was based on retrospective studies limited to small samples, and on clinical case reports. From these studies, the AAOMS estimated that the incidence of ONB was between 0.8 and $12 \%$, and affirmed that the risk of ONB among patients receiving intravenous bisphosphonates was significantly higher than among patients receiving them orally ${ }^{(19)}$.

Ruggiero et $\mathrm{al}^{(21)}$ established a clinical classification for lesions based on the levels of bone tissue destruction and the symptoms (Box 1). This has been widely used for prognosis and therapy in ONB cases. Regarding oral therapy, a systematic review showed that the prevalence of ONB was low $(1 / 10,000$ to $1 / 100,000$ patients/year $)^{(26)}$. In cases of therapy to control osteoporosis, this frequency was likewise low. A study demonstrated that out of 368 cases of ONB that were recorded, around 4\% were in women who had used $\mathrm{BF}$ to treat or prevent osteoporosis ${ }^{(27)}$. These estimates mostly involved cases treated using alendronate orally, and not using etidronate or ibandronate ${ }^{(28)}$ (Box 2).

Certain serum markers for predicting the risk of ONB among patients undergoing surgery on maxillary bones during their therapy with BFs have been suggested. Despite some controversy, and even though further studies are merited, telopeptide $\mathrm{C}$ of type I collagen (CTX) is considered to be an impor-

Box 1 - Clinical classification of lesions according to the level of bone tissue destruction and symptoms ${ }^{(21)}$.

\begin{tabular}{|c|}
\hline Clinical stage \\
\hline 0 - No clinical evidence of lesions, but with a risk of developing them. \\
\hline 1 - Exposure of necrotic bone tissue, but without symptoms. \\
\hline 2 - Exposure of symptomatic bone tissue, with or without secondary \\
infection and suppuration. \\
\hline $\begin{array}{c}\text { - Widespread exposure of symptomatic bone tissue, with secondary } \\
\text { infection, accompanied by some of the following items: pathological } \\
\text { fracture, extraoral fistula or bone lysis extending to the lower edge } \\
\text { of the mandible. }\end{array}$ \\
\hline
\end{tabular}


Box 2 - Bisphosphonate medications and their potency in relation to osteoporosis treatment.

\begin{tabular}{|c|c|c|c|}
\hline Generic name & $\begin{array}{c}\text { Commercial name/ } \\
\text { administration } \\
\text { route }\end{array}$ & Manufacturer & $\begin{array}{c}\text { Relative } \\
\text { potency }\end{array}$ \\
\hline $\begin{array}{c}\text { Sodium } \\
\text { alendronate 1,000 }\end{array}$ & Fosamax/ oral & Merck & $500-1,000$ \\
\hline Risedronate & Actonel/ oral & $\begin{array}{c}\text { Procter \& } \\
\text { Gamble }\end{array}$ & 5,000 \\
\hline Ibandronate & $\begin{array}{c}\text { Boniva/ oral/ } \\
\text { intravenous }\end{array}$ & Roche & $5,000-10,000$ \\
\hline
\end{tabular}

tant marker for osteoclastic activity, and this may be indicated for monitoring the bone reabsorption levels under these conditions ${ }^{(29)}$.

Oral rehabilitation among patients using oral BFs

The AAOMS recommends dental evaluation and complete rehabilitation before therapy with BFs is started. Dental preventive therapy is one of the factors shown to be effective for diminishing the risk of developing ONB, but it is incapable of eliminating the risk. Patients who are going to start treatment with BFs should present good oral health conditions. As part of the prior dental treatment, teeth that are no longer in a condition that can be restored should be eliminated. Invasive procedures (tooth extraction, implants, endodontic surgery and periodontal surgery) should be done at this time, and the mucosa at the intervention location needs to have healed (14-21 days) by the time of starting the therapy. Prophylaxis, caries control and restorative treatments should be implemented continually, and patients with total or partial prostheses should be assessed with regard to any presence of areas of trauma, especially in the lingual region of the mandible, since this is a region that is more liable to develop $\mathrm{ONB}^{(19)}$. It is important to emphasize that patients who have made use of oral BFs for more than three years, especially when associated with another risk factor such as continual use of corticosteroids, present a greater risk of developing ONB and losing implants due to a higher long-term failure rate. Patients with osteoporosis who make use of oral BFs may benefit from the possibility of interruption of therapy three months before undergoing invasive procedures with installation of osseointegrated implants, and then restarting the therapy at least three months after the surgery, thus leading to lower risk of developing postoperative and ONB complications ${ }^{(19)}$.

We noted in the current literature that some studies aiming to evaluate implants installed in patients using oral BFs found failure rates similar to those of patients with normal reactions ${ }^{(30,31)}$. However, at the same time, we noted an increasing number of clinical case reports on patients with longterm use of oral BFs who underwent rehabilitation with implants and developed ONB. Thus, it is clear that the length of use of BFs is a crucial factor in planning and rehabilitation with implant-supported prostheses, such that patients who have used oral BFs for more than three years enter a category of increased risk of developing ONB and losing the implants. It is important to emphasize that the latest protocol published by the AAOMS ${ }^{(19)}$ still places installation of osseointegrated implants in a high-risk category among oncological patients using intravenous BFs, thus contraindicating this procedure because of a lack of well-designed prospective studies with representative samples.

\section{FINAL REMARKS}

Osteonecrosis of the maxillae induced by bisphosphonates has been recognized as an important complication from prolonged treatment for osteoporosis using such medications. The risk factors associated with dental procedures related to tooth extraction and other surgical procedures with bone involvement, as well as infections of dental and periodontal origins. Therefore, dentists, general clinical physicians, oral and maxillofacial surgeons and geriatricians should remain alert to this problem and work in a multidisciplinary manner to promote early diagnosis and prevention of potential new cases. Future research should aim towards acquiring information on safety and treatment options relating to ONB. 


\section{REFERENCES}

1. NIH Consensus Development Panel on Osteoporosis Prevention, Diagnosis, and Therapy, March 7-29, 2000: highlights of the conference. South Med J. 2001;94(6):569-73.

2. Vestergaard P, Thomsen SV. Treating postmenopausal osteoporosis in women at increased risk of fracture - critical appraisal of bazedoxifene: a review. Int J Women Health.1:97-103.

3. Harvey N, Dennison E, Cooper C. Osteoporosis: impact on health and economics Nat Rev Rheumatol. 2010 Feb;6(2):99-105

4. Rao SS, Budhwar N, Ashfaque A. Osteoporosis in men. Am Fam Physician 2010;82(5):503-8.

5. Fernández-Tresguerres-Hernández-Gil I, Alobera-Gracia MA, del-Canto-Pingarrón M, Blanco-Jerez L. Physiological bases of bone regeneration I. Histology and physiology of bone tissue. Med Oral Patol Oral Cir Bucal. 2006;11(1):E47-51.

6. Naidu A, Dechow PC, Spears R, Wright JM, Kessler HP, Opperman LA. The effects of bisphosphonates on osteoblasts in vitro. Oral Surg Oral Med Oral Pathol Oral Radiol Endod. 2008;106(1):5-13.

7. Epstein S. Update of current therapeutic options for the treatment of postmenopausal osteoporosis. Clin Ther. 2006;28(2):151-73.

8. Pazianas M, Cooper C, Ebetino FH, Russell RG. Long-term treatment with bisphosphonates and their safety in postmenopausal osteoporosis. Ther Clin Risk Manag. 2010;6:325-43.

9. Kavanagh KL, Guo K, Dunford JE, Wu X, Knapp S, Ebetino FH, et al. Oppermann $U$. The molecular mechanism of nitrogen-containing bisphosphonates as antiosteoporosis drugs. Proc Natl Acad Sci U S A. 2006;103(20):7829-34.

10. Reszka AA, Rodan GA. Bisphosphonate mechanism of action. Curr Rheumatol Rep. 2003;5(1):65-74.

11. Migliorati CA. Bisphosphanates and oral cavity avascular bone necrosis. J Clin Oncol. 2003;21(22):4253-4.

12. Marx RE. Pamidronate (Aredia) and zoledronate (Zometa) induced avascular necrosis of the jaws: a growing epidemic. J Oral Maxillofac Surg. 2003;61(9):1115-7.

13. Wang J, Goodger NM, Pogrel MA. Osteonecrosis of the jaws associated with cancer chemotherapy. J Oral Maxillofac Surg. 2003;61(9):1104-7.

14. Carter GD, Goss AN. Bisphosphonates and avascular necrosis of the jaws. Aust Dent J. 2003;48(4):268.

15. Melo MD, Obeid G. Osteonecrosis of the jaws in patients with a history of receiving bisphosphonate therapy: strategies for prevention and early recognition. J Am Dent Assoc. 2005;136(12):1675-81.

16. Melo MD, Obeid G. Osteonecrosis of the maxilla in a patient with a history of bisphosphonate therapy. J Can Dent Assoc. 2005;71(2):111-3.

17. Migliorati CA, Schubert MM, Peterson DE, Seneda LM. Bisphosphonateassociated osteonecrosis of mandibular and maxillary bone: an emerging oral complication of supportive cancer therapy. Cancer. 2005;104(1):83-93.
18. Migliorati CA. Bisphosphonate-associated oral osteonecrosis. Oral Surg Oral Med Oral Pathol Oral Radiol Endod. 2005;99(2):135.

19. Ruggiero SL, Dodson TB, Assael LA, Landesberg R, Marx RE, Mehrotra B; Task Force on Bisphosphonate-Related Osteonecrosis of the Jaws, American Association of Oral and Maxillofacial Surgeons. American Association of Oral and Maxillofacial Surgeons position paper on bisphosphonate-related osteonecrosis of the jaw - 2009 update. Aust Endod J. 2009;35(3):119-30.

20. Robinson RE, Nahata MC, Hayes JR, Batisky DL, Bates CM, Mahan JD. Effectiveness of pretreatment in decreasing adverse events associated with pamidronate in children and adolescents. Pharmacotherapy. 2004;24(2):195-7.

21. Ruggiero SL, Fantasia J, Carlson E. Bisphosphonate-related osteonecrosis of the jaw: background and guidelines for diagnosis, staging and management. Oral Surg Oral Med Oral Pathol Oral Radiol Endod. 2006;102(4):433-41.

22. Lenz JH, Steiner-Krammer B, Schmidt W, Fietkau R, Mueller PC, Gundlach KK. Does avascular necrosis of the jaws in cancer patients only occur following treatment with bisphosphonates? J Craniomaxillofac Surg. 2005;33(6):395-403.

23. Hellstein JW, Marek CL. Bisphosphonate osteochemonecrosis (bis-phossy jaw): is this phossy jaw of the 21st century? J Oral Maxillofac Surg. 200;63(5):682-9.

24. Lugassy G, Shaham R, Nemets A, Ben-Dor D, Nahlieli O. Severe osteomyelitis of the jaw in long-term survivors of multiple myeloma: a new clinical entity. Am J Med. 2004;117(6):440-1.

25. Boonyapakorn T, Schirmer I, Reichart PA, Sturm I, Massenkeil G. Bisphosphonate-induced osteonecrosis of the jaws: prospective study of 80 patients with multiple myeloma and other malignancies. Oral Oncol. 2008;44(9):857-69.

26. Khosla S, Burr D, Cauley J, Dempster DW, Ebeling PR, Felsenberg D, et al. Bisphosphonate-associated osteonecrosis of the jaw: report of a task force of the American Society for Bone and Mineral Research. J Bone Miner Res. 2007;22(10):1479-91

27. Woo SB, Hellstein JW, Kalmar JR. Narrative [corrected] review: bisphosphonates and osteonecrosis of the jaws. Ann Intern Med. 2006;144(10):753-61.

28. Pazianas M, Miller P, Blumentals WA, Bernal M, Kothawala P. A review of the literature on osteonecrosis of the jaw in patients with osteoporosis treated with oral bisphosphonates: prevalence, risk factors, and clinical characteristics. Clin Ther. 2007;29(8):1548-58.

29. Lazarovici TS, Yahalom R, Taicher S, Schwartz-Arad D, Peleg O, Yarom N. Bisphosphonate-related osteonecrosis of the jaw associated with dental implants. J Oral Maxillofac Surg. 2010;68(4):790-6.

30. Madrid C, Sanz M. What impact do systemically administrated bisphosphonates have on oral implant therapy? A systematic review. Clin Oral Implants Res. 2009;20(Suppl 4):87-95.

31. Javed F, Almas K. Osseointegration of dental implants in patients undergoing bisphosphonate treatment: a literature review. J Periodontol. 2010;81(4):479-84. 